\title{
ORIGIN AND DIVERSIFICATION OF PHILIPPINE BULBULS
}

\author{
BY
}

\author{
Carl H. Oliveros
}

Submitted to the graduate degree program in Ecology and Evolutionary Biology and the Graduate Faculty of the University of Kansas in partial fulfillment of the requirements for the degree of Master's of Arts

Robert G. Moyle, Ph.D. Chairperson

Committee members

A. Townsend Peterson, Ph.D.

Rafe M. Brown, Ph.D.

Mark T. Holder, Ph.D.

Date defended: 28 April 2009 
The Thesis Committee for Carl H. Oliveros certifies that this is the approved version of the following thesis:

ORIGIN AND DIVERSIFICATION OF PHILIPPINE BULBULS

Committee:

Robert G. Moyle, Ph.D. Chairperson

A. Townsend Peterson, Ph.D.

Rafe M. Brown, Ph.D.

Mark T. Holder, Ph.D.

Date approved: 28 April 2009 


\section{TABLE OF CONTENTS}

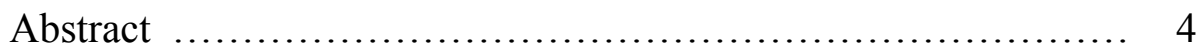

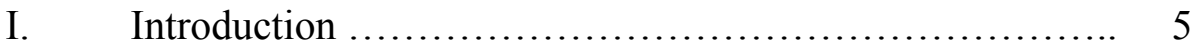

II. Materials and Methods................................ 10

III. Results ........................................... 17

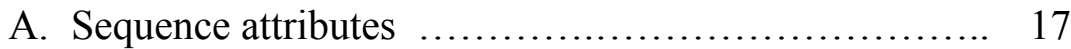

B. Phylogenetic relationships $\ldots \ldots \ldots \ldots \ldots \ldots \ldots \ldots \ldots \ldots$

IV. Discussion ......................................... 25

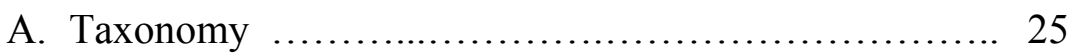

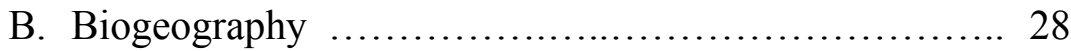

1 Patterns of colonization ..................... 29

2 Diversification of Philippine bulbuls ........ 33

Acknowledgements ....................................... 36

References ............................................ 37 


\begin{abstract}
We examine the origin and diversification of Philippine bulbuls using a phylogenetic framework. We used maximum likelihood and Bayesian methods to construct trees from DNA sequences of two mitochondrial and two nuclear genes obtained from 11 Philippine bulbul species as well as 32 other Asian and African taxa. We found eight independent colonization events of bulbuls to the Philippines, including one clade comprising Philippine members of the genus Ixos that underwent extensive diversification within the archipelago. Each Philippine clade of bulbuls invaded either the Palawan region or the oceanic islands of the Philippines, but not both. Genetic data reveal at least 5 lineages that warrant recognition as full species. This study underscores how Philippine avian diversity is currently underestimated and highlights the need for further phylogenetic studies in other Philippine bird groups.
\end{abstract}




\section{INTRODUCTION}

Oceanic island archipelagos provide a unique microcosm for studies of diversification. The stark geographic boundaries and comparatively simple floras and faunas remove many confounding factors present in continental regions. The Philippine archipelago, comprising over 7,000 islands, is one of the largest on Earth, yet relatively little is known about the origins and diversification history of most of its endemic flora and fauna. A basic question of all archipelagoes, and the Philippines in particular, is the relative importance of colonization and in situ diversification in forming insular biotas. Among Philippine vertebrates, reptiles, amphibians, and mammals show high levels of endemism, suggesting a substantial role for diversification within the archipelago (Kennedy et al., 2000; Ong et al., 2002). This is supported by phylogenetic studies of select clades within these groups (e.g., Evans et al., 2003; Jansa et al., 2006; McGuire and Kiew, 2001). In contrast, birds show relatively low levels of endemism and suggest, in keeping with their volant nature, that colonization may be a more important driver of species diversity. That is, origins of the Philippine bird fauna involved more assembly whereas other vertebrate faunas involved greater diversification.

The Philippine archipelago has had a complex geological history but the major stages are now fairly well understood as summarized in Hall (2002) and Yumul et al. (2008). The western islands of Palawan and Mindoro are composed of continental crust that rifted from the margins of southern China and rafted to their current 
position. Most or all of this land was probably submerged at some point during the transit across the South China Sea. Parts of Mindanao - the Zamboanga Peninsula and the Daguma Range in the southwest - also have continental origins. These fragments were in isolation for a long period of time but they have been in contact with central Mindanao since the middle Miocene. The rest of the archipelago is oceanic, arising de novo since the late Cretaceous and throughout the Cenozoic from a complex system of island arcs between the Eurasian and the Philippine Sea plates. Individual fragments have moved in a dynamic fashion, changing direction and pace, but this belt of oceanic islands has been moving in a general northwesterly direction since the early Cenozoic. During the last glacial maximum in the Pleistocene, sea levels are estimated to have been $120 \mathrm{~m}$ below current levels exposing land connections between some Philippine islands (Heaney, 1986; Voris, 2000; Fig. 1).

Early workers traced the origins of Philippine bird fauna to the Sunda, Palearctic and Australasian regions (e.g., Dickerson, 1928). The Sunda region is considered the chief colonization source (Dickinson et al., 1991) and the Palawan group of islands and the Sulu archipelago are seen as important invasion routes to the Philippines (Diamond and Gilpin, 1983). The dominant framework in the study of diversification of Philippine fauna in the last two decades has been that Pleistocene islands during the last glacial maximum define the limits of homogenous populations, each of which is a center of endemism (Heaney, 1986). These patterns of colonization and diversification have been studied in a phylogeographic context in birds for a few 


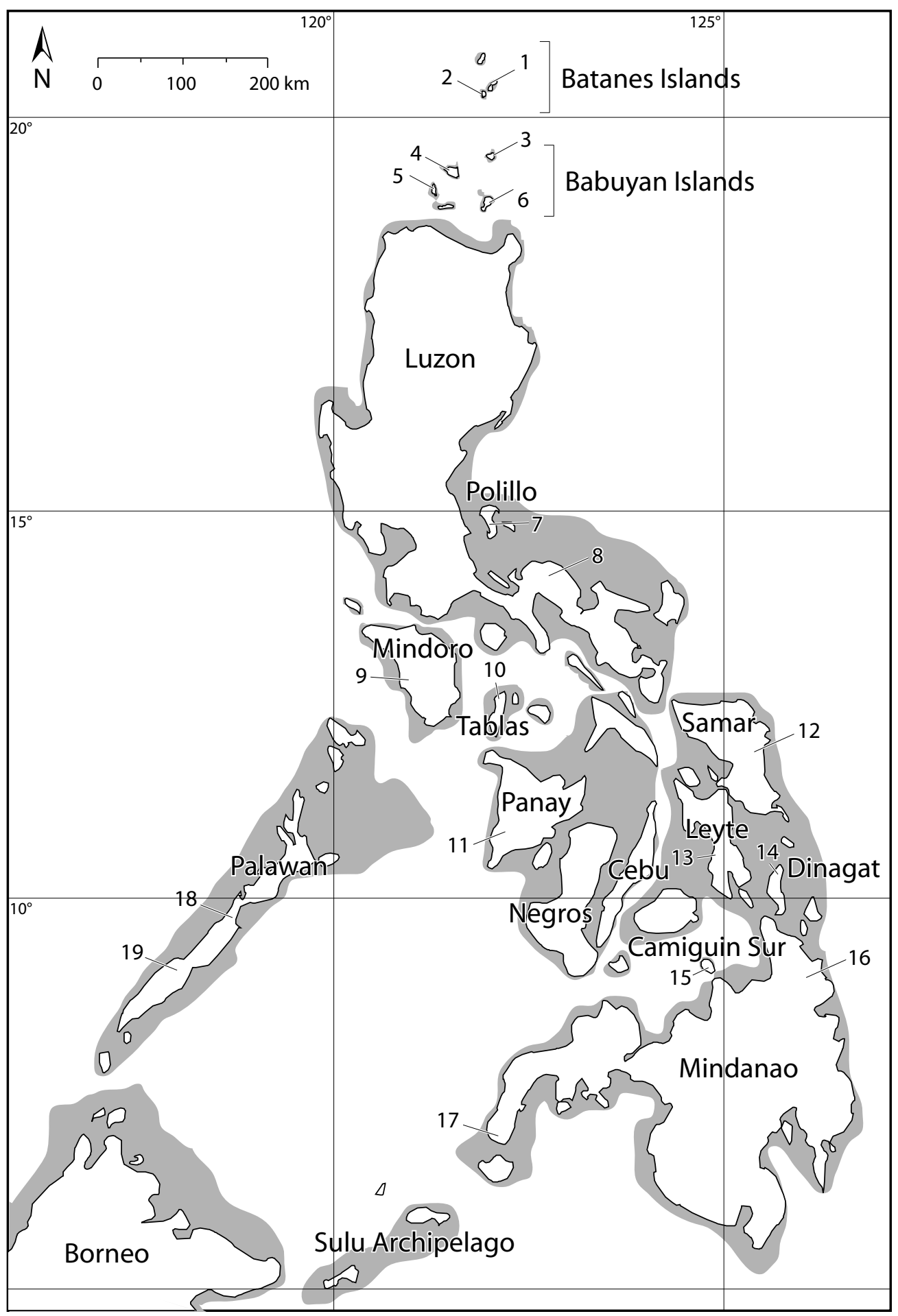

Figure 1. Location of sampling localities. Numbers correspond to those in Table 1. Light gray areas show late Pleistocene islands based on Heaney (1986). 
species (Jones and Kennedy, 2008a, b) but no thorough investigations have been carried out at higher taxonomic levels.

Bulbuls (Pycnonotidae) are ubiquitous residents of the tropical and semi-temperate Old World and are ideal subjects to study colonization and diversification patterns in the Philippines. Bulbuls are found throughout Southeast Asia, with high species ririchness in the Sunda region (e.g., 22 species on Borneo). They include some of the commonest species in SE Asian forests, and comprise a sizable proportion of the species diversity of frugivores. Despite supposed strong dispersal ability, as evidenced by their presence throughout the oceanic Philippines, the family is almost completely truncated by Wallace's line: only a single genus, Thapsinillas, occurs in the Moluccas. The family is widespread throughout the Philippine archipelagooccurring even on very small and remote islands. The Philippines harbors 11 bulbul species that are placed in five genera. We follow the taxonomy of Fishpool and Tobias (2005) except for the taxonomic treatment of Iole palawanensis where we follow Dickinson (2003). Six species of bulbuls are endemic to the Philippines: five are endemic to oceanic islands of the Philippines (Pycnonotus urostictus, Ixos philippinus, I. rufigularis, I. everetti and I. siquijorensis) and one occurs only in the Palawan region (Iole palawanensis). Four species are shared with the Sunda region, of which three are found in the Philippines only on Palawan (Pycononotus atriceps, P. plumosus, and Alophoixus bres) and the other is distributed throughout the oceanic Philippines (Pycnonotus goiavier) except the Batanes-Babuyan island chain (Fig. 1). 
The other non-endemic species, Microscelis amaurotis, occurs only on small islands in the Batanes-Babuyan island group north of Luzon and has a range that extends north through Taiwan and the Ryukyu archipelago to northern Japan and the Korean peninsula. Many of these species include multiple described subspecies and some workers have suggested that some of these races merit recognition as full species (Fishpool and Tobias, 2005; Allen, 2006; Peterson, 2006).

A recently published molecular phylogeny of bulbuls (Moyle and Marks 2006) recovered two main lineages - one exclusively African and the other mostly Asian. Their study included only five Philippine species and all but one were widespread species sampled from localities outside of the Philippines. In the present study, we use the Moyle and Marks (2006) phylogenetic framework for bulbuls to examine the origin and diversification of Philippine members of the family. In particular, we address the following questions: 1) How many independent colonization events spawned the Philippine bulbul radiation? 2) Do temporal patterns of colonization history suggest clustered dispersal events, potentially facilitated by specific historical factors, or random sweepstakes dispersal? 3) Do genetic data reflect Palawan Island's recent land connection to the islands of the Sunda Shelf? 4) What general patterns of colonization and diversification can be inferred from the genealogical history of the Philippines' bulbul fauna? 


\section{MATERIALS AND METHODS}

We used DNA sequence data for 28 species from Moyle and Marks' (2006) study of bulbul systematics that used the following markers: the entire second and third subunits of mitochondrial nicotinamide adenine dinucleotide dehydrogenase (ND2 and ND3) and the seventh intron of the nuclear Beta-Fibrinogen (Fib7). We expanded this dataset by adding 46 individuals and sequencing an additional nuclear gene, the fifth intron of the Transforming Growth Factor $\beta 2$ (TGF5), for all samples. In total, ingroup sampling (Table 1) consisted of 74 individuals representing 43 recognized bulbul species (Fishpool and Tobias, 2005). All 11 species that occur in the Philippines, including 18 of the 25 named subspecies, were sampled. For most subspecies, we sampled 1 individual but we added additional individuals if they were collected from different localities or from outside the Philippines. Our ingroup sampling included all bulbul species that occur on Borneo, with the exception of Alophoixus finschii and Pycnonotus nieuwenhuisii. Two African species (Pycnonotus barbatus and Pycnonotus nigricans) and one Malagasy species (Hypsipetes madagascariensis) that were previously shown to form part of the largely Asian clade (Moyle and Marks, 2006) were also included in the ingroup. We chose Bleda canicapillus, Criniger calurus, Phyllastrephus icterinus and Calyptocichla serina as outgroup taxa because they belong to the African radiation sister to the mostly Asian clade of bulbuls (Moyle and Marks, 2006, Johansson et al., 2007). 


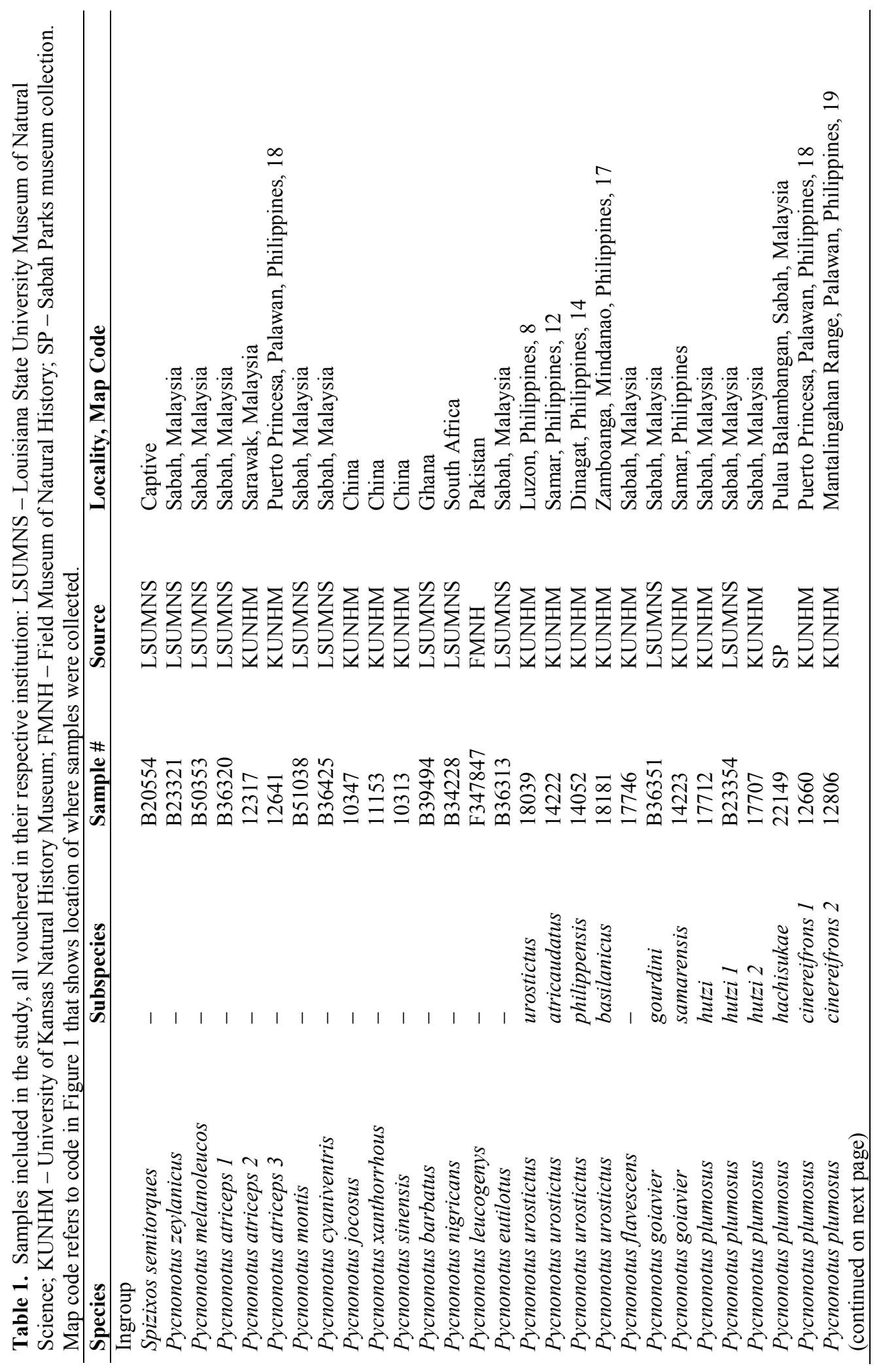




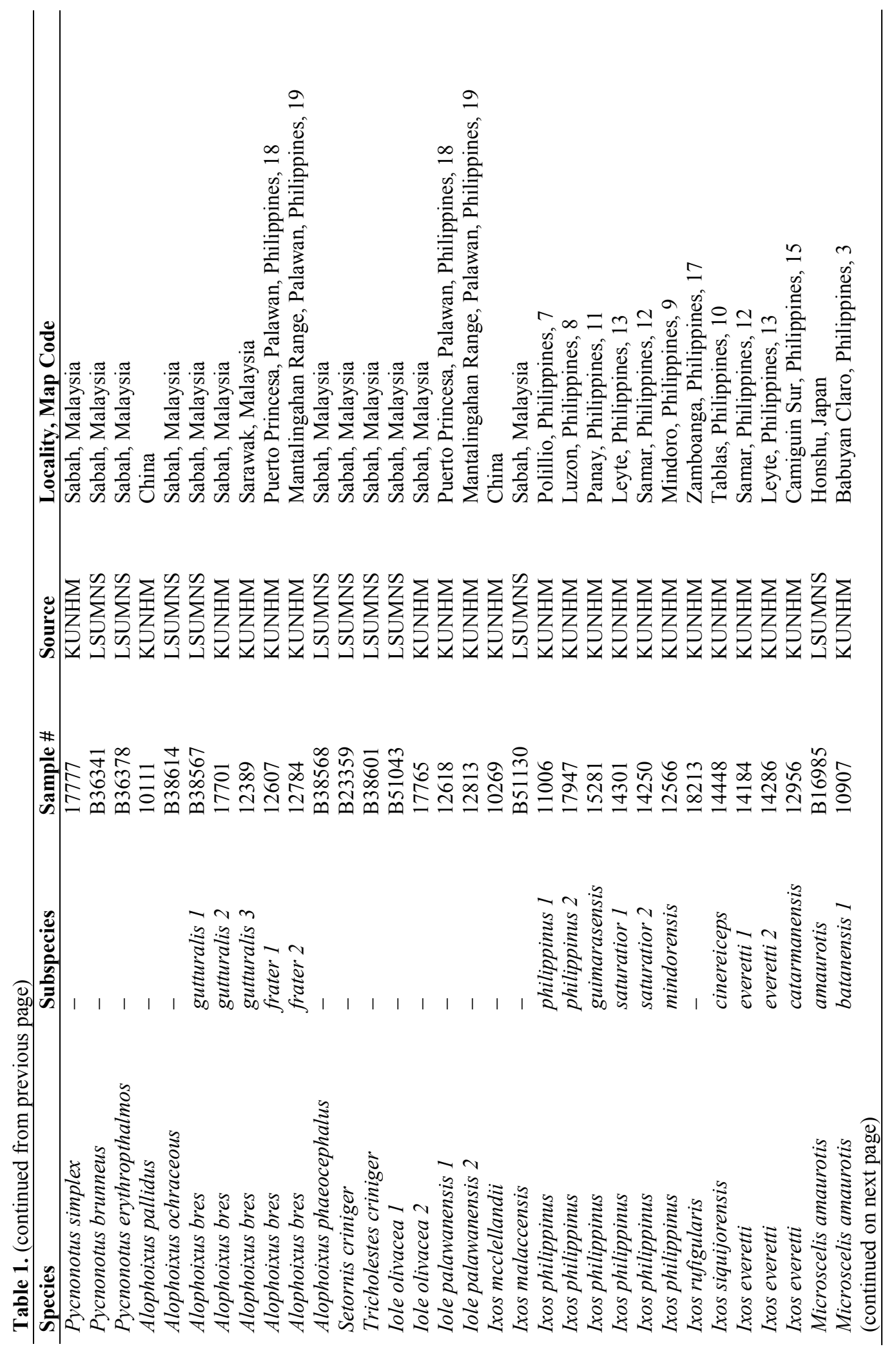




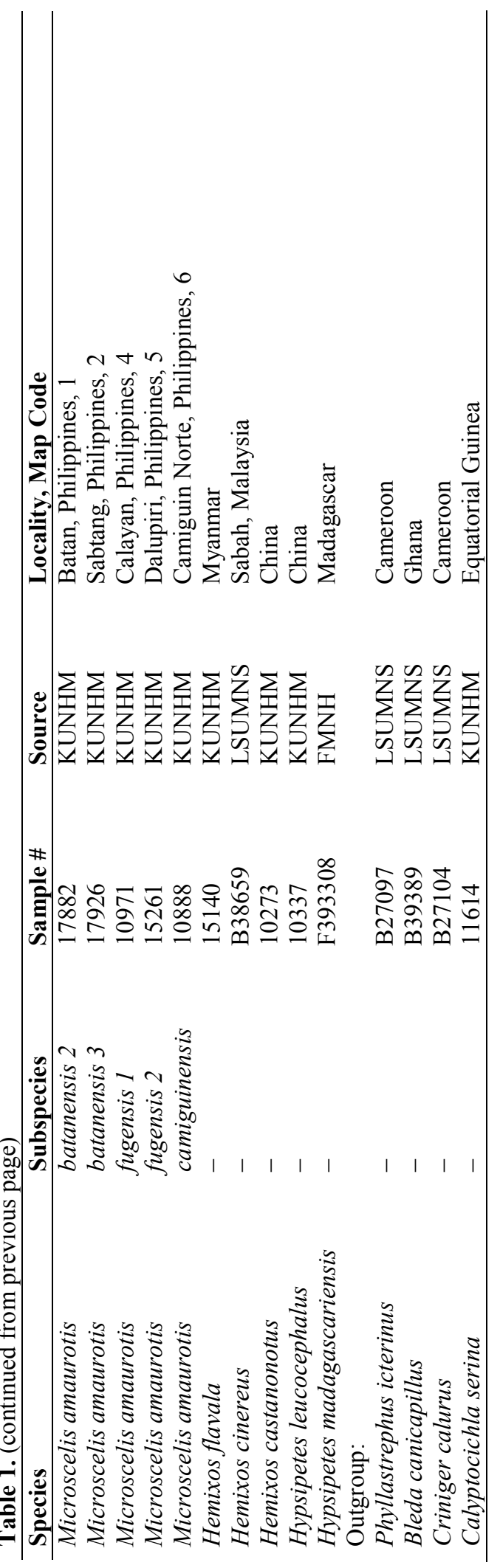


We extracted genomic DNA from pectoral muscle or liver tissue using the DNeasy Blood and Tissue Kit (Qiagen Inc., Valencia, CA) following the manufacturer's protocol. We amplified target DNA fragments by performing polymerase chain reaction (PCR) using a combination of external and internal primers (Table 2). We purified PCR products with ExoSAP-IT (US78201, Amersham Biosciences, Piscataway, NJ). Purified PCR products were then sequenced with ABI Prism BigDye Terminator chemistry (Ver. 3.1; Applied Biosystems, Foster City, CA) using the same primers used for PCR. Cycle sequencing products were purified through precipitation in 70\% ethanol and then analyzed on an ABI 134 Prism 3130xl Genetic Analyzer (Applied Biosystems, Foster City, CA). We used Sequencher 4.7 (Gene Codes Corp., Ann Arbor, MI) to reconcile complementary gene sequence contigs and align sequences across taxa.

Maximum likelihood (ML) heuristic tree searches were performed using GARLI 0.96 (Zwickl, 2008) on the combined 4-gene dataset. We selected the ML tree from 10 replicate searches. Node support was assessed by conducting ML heuristic searches on 500 bootstrap replicates of the data. We performed Bayesian analysis using Mr. Bayes 3.1 (Huelsenbeck and Ronquist, 2001; Ronquist and Huelsenbeck, 2003) with the data divided into five partitions: one partition for each codon position in the combined ND2 and ND3 dataset; and one partition for each of the nuclear introns. All parameters (except topology) were unlinked between partitions. We ran four Markov chains for 2 million generations. Markov chains were sampled every 100 
generations, yielding 20,000 parameter point estimates. Likelihood scores were examined for stationarity and all prior samples were discarded as burn in. We conducted similar ML and Bayesian analyses on each intron and on the combined mitochondrial gene dataset (ND2 + ND3). We used MrModeltest 2.2 (Nylander, 2004) in conjunction with PAUP* $4.0 \mathrm{~b} 10$ (Swofford, 2002) to select the appropriate model of sequence evolution under the Akaike Information Criterion (AIC) for the entire dataset and its subsets.

Table 2. Primers used in this study.

\begin{tabular}{|c|c|c|c|}
\hline Gene & $\begin{array}{l}\text { Primer } \\
\text { name }\end{array}$ & Sequence (5' to $\left.3^{\prime}\right)$ & Reference \\
\hline \multirow[t]{2}{*}{ ND3 } & L10755 & GACTTCCAATCTTTAAAATCTGG & Chesser, 1999 \\
\hline & L11151 & GACTGCGACAAAATCCCATTCCA & Chesser, 1999 \\
\hline \multirow[t]{9}{*}{ ND2 } & L5215 & TATCGGGCCCATACCCCGAAAAT & Hacket, 1996 \\
\hline & L5758 & GGCTGAATRGGMCTNAAYCARAC & Johnson \& Sorenson, 1998 \\
\hline & H6313 & СТCTTATTTAAGGCTTTGAAGGC & Johnson \& Sorenson, 1998 \\
\hline & H1064 & CTTTGAAGGCCTTCGGTTTA & Drovetski et al., 2004 \\
\hline & $500 \mathrm{~L}$ & GAATAGGACTAAACCAAACAC & Filardi \& Moyle, 2005 \\
\hline & SWH & CCTAGGTGGGAGATRGAGGA & Sheldon et al., 2005 \\
\hline & $503 \mathrm{~L}$ & TAGGMCTWAAYCARACMC & this study \\
\hline & $328 \mathrm{~L}$ & CCRTTYCACTTYTGATTCCC & this study \\
\hline & 479L & TTTCTACCGCCCTAGGAGGG & this study \\
\hline \multirow[t]{7}{*}{ Fib7 } & FIB-BI7L & TCCCCAGTAGTATCTGCCATTAGGGTT & Prychitko \& Moore, 1997 \\
\hline & FIB-BI7U & GGAGAAAACAGGACAATGACAATTCAC & Prychitko \& Moore, 1997 \\
\hline & FIB-BI7Lb & CAGTGCTCTATTATGTACTTTAC & Sheldon et al., 2005 \\
\hline & FIB-BI7Lc & TGTAATYASGTATTAAGCAC & this study \\
\hline & FIB-BI7Uc & AGAAGAYRGGMGYTCAGTTG & this study \\
\hline & FIB-BI7Ld & CATGGTGCACTCAGAAAGTAAAGC & this study \\
\hline & FIB-BI7Ud & GCTAAAYGTCTGTGCAGTTCCC & this study \\
\hline \multirow[t]{4}{*}{ TGF5 } & TGF5 & GAAGCGTGCTCTAGATGCTG & Bures et al., 2002 \\
\hline & TGF6 & AGGCAGCAATTATCCTGCAC & Bures et al., 2002 \\
\hline & TGF5alt & ATCTGGGGTGATTCCCACATGC & Moyle et al., 2009 \\
\hline & TGF6alt & ACTCAAGTGTWTTTCTCCAGGTCC & Moyle et al., 2009 \\
\hline
\end{tabular}


We performed Shimodaira-Hasegawa (SH) Tests using PAUP* 4.0b10 (Swofford, 2002) and GARLI 0.96 (Zwickl, 2008) to test monophyly of currently recognized species that were recovered as non-monophyletic in the ML and Bayesian analyses.

To estimate relative timing of colonization events we produced an ultrametric tree and erected $95 \%$ confidence intervals for node heights using BEAST version 1.4.8 (Drummond and Rambaud, 2007). We chose not to place dates on the ultrametric tree because reliable calibration points are not available for bulbuls. We used the same data partitioning scheme and models of sequence evolution as the Bayesian analysis on the concatenated data. We also constrained topologies in the MCMC run to the Bayesian consensus tree obtained in the first analysis. Rate homogeneity along branches of the phylogeny was tested using a likelihood ratio test (Hasegawa et al., 1985). A strict molecular clock hypothesis for the dataset was rejected $(\mathrm{p}<0.001)$ thus a relaxed clock model (Drummond et al., 2006) with uncorrelated rates drawn from a lognormal distribution was selected. We ran an MCMC for 10 million generations and logged parameters every 100 generations. We discarded the first 6.5 million generations as burn-in. 


\section{RESULTS}

\section{A. Sequence attributes}

The final dataset had a total alignment length of 2,907 bp of combined DNA sequences from ND2, ND3, Fib7 and TGF5 (Table 3). We sequenced partial or entire genes for all samples except for the TGF5 intron of Pycnonotus montis and Iole olivacea 1. 1,118 characters (38\%) were parsimony informative (Table 3). All sequences were deposited in GenBank (Accession Nos. XXXXX-XXXXX). Aligned ND2 and ND3 sequences contained no stop codons and appeared to be of mitochondrial origin. Overlapping fragments contained no conflicts, base composition was relatively homogenous across taxa, codon positions contained expected relative divergences $(3>1>2)$, and resulting relationships contained no highly suspect arrangements. Aligned Fib7 and TGF5 sequences contained several inferred insertions or deletions (indels), which were mapped on the inferred tree to provide additional support for phylogenetic relationships (Johnson et al. 2001; Moyle, 2004; Moyle and Marks, 2006). Models of sequence evolution used for the ML and Bayesian analyses were: the general time reversible model with gamma-distributed rates among sites and invariant sites $(\mathrm{GTR}+\mathrm{I}+\mathrm{G})$ for the concatenated data, the combined mitochondrial genes and each of their partition by codon position; and the general time reversible model with gamma-distributed rates among sites $(\mathrm{GTR}+\mathrm{G})$ for each of the introns (Table 3). 
Table 3. Sequence attributes and models of sequence evolution used for ML and Bayesian analyses.

\begin{tabular}{|c|c|c|c|c|}
\hline & ND2 & ND3 & Fib7 & TGF5 \\
\hline Aligned length & 1041 & 351 & 919 & 596 \\
\hline Sequence length & $339-1041$ & 351 & $545-868$ & $316-592$ \\
\hline Number variable & 613 & 197 & 341 & 198 \\
\hline Number informative & 557 & 182 & 229 & 150 \\
\hline Models & & & & \\
\hline ML (combined data) & \multicolumn{4}{|c|}{$\mathrm{GTR}+\mathrm{I}+\mathrm{G}$} \\
\hline ML (individual loci) & GTR & & $\mathrm{GTR}+\mathrm{G}$ & $\mathrm{GTR}+\mathrm{G}$ \\
\hline $\begin{array}{l}\text { Bayesian (combined data - } \\
\text { partitions) }\end{array}$ & $\begin{array}{l}\text { Codon Pos } 1 \\
\text { Codon Pos } 2 \\
\text { Codon Pos } 3\end{array}$ & $\begin{array}{l}+I+G \\
+I+G \\
+I+G\end{array}$ & $\mathrm{GTR}+\mathrm{G}$ & $\mathrm{GTR}+\mathrm{G}$ \\
\hline Bayesian (individual loci) & $\begin{array}{l}\text { Codon Pos } 1 \\
\text { Codon Pos } 2 \\
\text { Codon Pos } 3\end{array}$ & $\begin{array}{l}+I+G \\
+I+G \\
+I+G\end{array}$ & $\mathrm{GTR}+\mathrm{G}$ & $\mathrm{GTR}+\mathrm{G}$ \\
\hline
\end{tabular}

${ }^{a}$ combined ND2 and ND3 sequence

\section{B. Phylogenetic relationships}

Maximum likelihood (not shown) and Bayesian (Fig. 2) analyses of the entire dataset produced well-resolved and mostly congruent topologies. Minor incongruences between the Bayesian consensus tree and the ML tree were characterized by low bootstrap support in the ML tree. Topologies from ML and Bayesian analysis of individual genes and the combined mitochondrial data (not shown) were almost entirely consistent with the Bayesian consensus tree inferred from the concatenated data. The only highly supported node incongruent with Fig. 2 was inferred from the mitochondrial gene dataset and placed Ixos philippinus guimarasensis sister to the clade formed by I. p. mindorensis and I. siquijorensis.

The topology recovered from our analyses was very similar to that inferred by Moyle and Marks (2006) because it was based in large part on the same data. Three main clades were inferred in this mostly Asian lineage of bulbuls. The first clade (Clade A, 


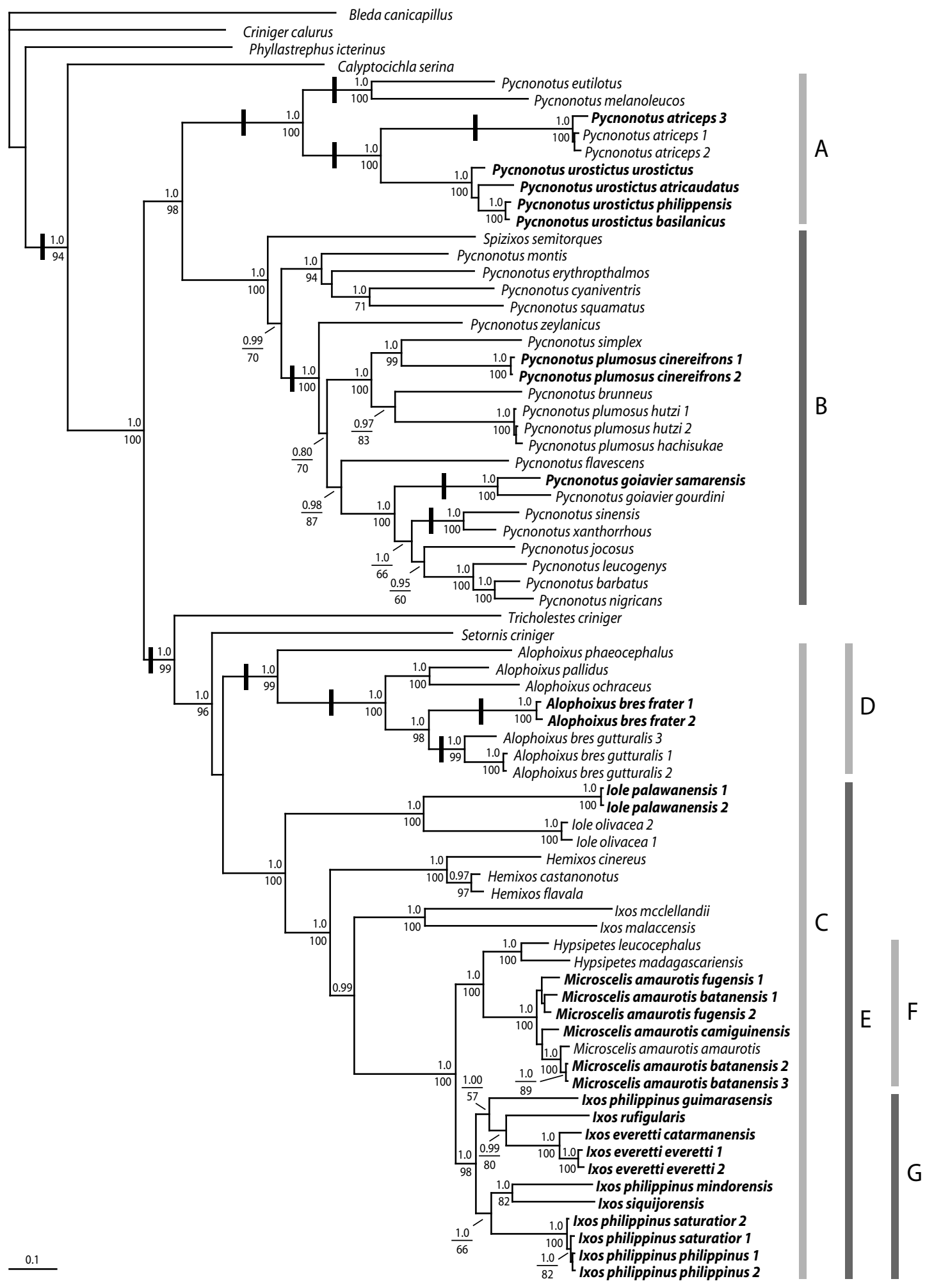

Figure 2. Bayesian consensus tree inferred from the combined sequences of the mitochondrial genes ND2 and ND3 and the nuclear introns Fib7 and TGF5. Philippine samples appear in bold. Numbers above nodes indicate Bayesian posterior probability $>95 \%$, numbers below indicate ML bootstrap support $>50 \%$. Black bars indicate the inference of indels in the introns. 
Fig. 2) included four species of the genus Pycnonotus (P. eutilotus, P. melanoleucos, P. atriceps, and P. urostictus) and received high node support. This set of species was clearly distinguished from the other Pycnonotus species by a long deletion (ca. $203 \mathrm{bp}$ ) in the Fib7 gene. Two of the species (P. atriceps and P. urostictus), which both occur in the Philippines but are allopatric, were most closely related to each other and share a 1-bp indel in TGF5. Monophyly of each species was well supported. Little genetic divergence (hereafter, genetic divergence refers to uncorrected p-distance in the ND2 data, unless otherwise stated) was detected between Bornean and Palawan individuals of $P$. atriceps (Table 4). On the other hand, genetic divergence between subspecies of $P$. urostictus varied from as high as 0.047 to as low as 0.008 (Table 4). A 38-bp deletion in Fib7 was common to P. $u$. atricaudatus and P. u. urostictus.

Table 4. Uncorrected p-distances in mitochondrial ND2 gene sequences of selected individuals.

\begin{tabular}{|c|c|}
\hline Taxon pairs & $p$-distance \\
\hline Pycnonotus atriceps 1 and $P$. atriceps 3 & 0.019 \\
\hline Pycnonotus atriceps 1 and $P$. urostictus urostictus & 0.148 \\
\hline Pycnonotus urostictus atricaudatus and $P . u$. basilanicus & 0.047 \\
\hline Pycnonotus urostictus philippensis and $P . u$. basilanicus & 0.008 \\
\hline Pycnonotus plumosus cinereifrons 1 and $P$. simplex & 0.120 \\
\hline Pycnonotus plumosus hutzi 1 and $P$. p. hachisukae & 0.004 \\
\hline Pycnonotus goiavier samarensis and $P$. g. gourdini & 0.071 \\
\hline Alophoixus bres frater 1 and A. b. gutturalis 1 & 0.109 \\
\hline Alophoixus bres gutturalis 1 and $A$. b. gutturalis 3 & 0.058 \\
\hline Iole palawanensis 1 and Iole olivacea 2 & 0.169 \\
\hline Microscelis amaurotis fugensis 1 and M. a. batanensis 2 & 0.044 \\
\hline Microscelis amaurotis amaurotis and M. a. batanensis 3 & 0.016 \\
\hline Ixos philippinus guimarasensis and I. p. mindorensis & 0.122 \\
\hline Ixos philippinus guimarasensis and I. rufigularis & 0.116 \\
\hline Ixos philippinus mindorensis and I. siquijorensis & 0.106 \\
\hline Ixos philippinus saturatior 1 and I. p. mindorensis & 0.110 \\
\hline Ixos rufigularis and I. everetti everetti 1 & 0.101 \\
\hline Ixos everetti everetti 1 and I. e. catarmanensis & 0.034 \\
\hline Ixos philippinus saturatior 1 and I. p. philippinus 1 & 0.003 \\
\hline
\end{tabular}


The second main clade (Clade B, Fig. 2) was sister to Clade A and consisted of all the other species of Pycnonotus and included Spizixos semitorques. In this clade a polyphyletic $P$. plumosus was recovered with high ML bootstrap support and posterior probabilities, although an SH Test performed could not reject monophyly of the species $(p=0.165)$. The Philippine population of this species $P$. p cinereifrons was sister to P. simplex while its Bornean populations, P. p. hutzi and P. p. hachisukae, were sister to P. brunneus. The genetic divergence between $P$. p . cinereifrons and its sister taxon was very high (0.120) while the two Bornean subspecies P.p. hutzi and P.p. hachisukae showed little genetic difference between them (Table 4). Another Philippine species in Clade B showed substantial genetic divergence (0.071) between the Philippine subspecies $P$. goiavier samarensis and the Sunda race P. g. gourdini (Table 4). A 7-bp indel in Fib7 and a 4-bp indel in TGF5 were shared by both samples of $P$. goiavier.

The third main clade (Clade C, Fig. 2), formed by 8 genera (Tricholestes, Setornis, Hypsipetes, Alophoixus, Iole, Ixos, Hemixos and Microscelis) had strong node support and was sister to the clade formed by Clade A and Clade B. The study of Moyle and Marks (2006) placed Clade A as the most basal branch among the three main clades and this arrangement had high posterior probability (99\%) but only moderately low ML bootstrap support (70\%) in their study. The monotypic genus Tricholestes from the Malay Peninsula and the Greater Sundas branched basally in Clade C with strong 
node support. Another monotypic genus, Setornis of the Greater Sundas diverged next but this node had low support. Aside from these two basal monotypic genera, Clade C contained two main sub-groups: a well-supported clade of the genus Alophoixus (Clade D, Fig. 2) and a lineage formed by the genera Iole, Hemixos, Ixos, Hypsipetes and Microscelis (Clade E, Fig. 2), previously lumped together in the genus Hypsipetes. In Clade E, all genera were recovered as monophyletic with the exception of the genus Ixos (see below).

In Clade D, relationships among taxa of the genus Alophoixus were well-resolved. A. phaeocephalus was sister to all other species in the genus. A monophyletic $A$. bres was sister to a clade formed by A. pallidus and A. ochraceus. The inference of three distinct indels in the Fib7 gene provided additional support to the recovered topology. However, a 13-bp deletion shared by A. pallidus, A. ochraceus and A. bres gutturalis was not shared with the Palawan taxon A. bres frater. This Palawan taxon was genetically distinct from the Bornean A. b. gutturalis (Table 4). These two populations were further distinguished by three apomorphic indels that were present only in one population but not in both. Even within Borneo, considerable genetic divergence was found between Sarawak and Sabah samples (Table 4). This pattern of genetic differentiation between bird populations within Borneo has also been noted in Enicurus leschenaulti (Moyle et al., 2005) and Copsychus saularis (Sheldon et al., in press). 
In Clade E, the genus Iole was the most basal lineage. Within this genus, the Palawan-endemic I. palawanensis showed deep genetic divergence (0.169, Table 4) from the Bornean taxon I. olivacea. The genus Hemixos and a clade formed by Ixos mclellandii and Ixos malaccensis were next to branch out sequentially from the base of Clade E. While this relationship received high posterior probability, ML bootstrap support was very low. Moyle and Marks (2006) inferred a sister relationship between Hemixos cinereus and Ixos malaccensis with moderately high node support.

The youngest lineage in Clade E included two sister clades: one formed by the genera Hypsipetes and Microscelis (Clade F) and the other comprising all Philippine species of the genus Ixos (Clade G). In Clade F, Microscelis amaurotis, was sister to a clade formed by two species of the genus Hypsipetes. Considerable genetic differences were found among different island populations of M. amaurotis within the Philippines but little genetic divergence was seen between populations from the Batanes Islands and Honshu, Japan (Table 4). Genealogical relationships between island populations of this species were not well resolved.

In the exclusively Philippine Clade G, a polyphyletic Ixos philippinus was evident with strong node support, although an SH Test performed could not reject that a monophyletic Ixos philippinus could as well explain the data $(p=0.060)$. Within $I$. philippinus three distinct lineages were inferred: I. p. guimarasensis from the western Visayas; I. p. mindorensis from the island of Mindoro; and a combined I. p. 
philippinus and I. p. saturatior, from Luzon, eastern Visayas and Mindanao. I. p. guimarasensis was sister to a clade formed by I. rufigularis and I. everetti whereas I. p. mindorensis was sister to I. siquijorensis. The position of the third I. philippinus lineage was uncertain. I. everetti was monophyletic. These arrangements received high support from Bayesian posterior probabilities although a few received low or moderate ML bootstrap support. Genetic differences between these lineages were greater than 0.100 (Table 4). 


\section{DISCUSSION}

\section{A. Taxonomy}

Proposing a complete taxonomic revision of Asian bulbuls is beyond the scope of this study but some changes in the taxonomy of Philippine bulbuls are mandated based on

these data. Individuals from two taxa, Pycnonotus plumosus and Ixos philippinus, did not form single, monophyletic clades. Although monophyly of each of these two taxa was not rejected by an SH Test, this test is considered very conservative (Goldman et al., 2000; Buckley and Cunningham, 2002) and has a relatively low power of discrimination. Because the polyphyly of these species received strong nodal support from ML bootstrap proportions and posterior probabilities these two taxa warrant taxonomic changes, as follows. The Palawan population P. p. cinereifrons is genetically greatly divergent $(0.136-0.138)$ from the Bornean taxa $P . p$. hutzi and $P$. p. hachisukae, and does not form a clade with them, but rather is sister to $P$. simplex. Morphological differences between populations on Borneo and Palawan are subtle (Fishpool and Tobias, 2005), but when combined with the large genetic differences and lack of monophyly, these data compel recognition of the Palawan population as a distinct species Pycnonotus cinereifrons (Tweedale, 1878). We lack samples of the other two subspecies, P. p. porphyreus and the nominate form, which occur in the western Greater Sunda Islands. However, based on geography it is unlikely that they are closely related to the Palawan subspecies and so it would be appropriate to retain them under $P$. plumosus until further data suggest otherwise. 
Within the currently recognized taxon Ixos philippinus, at least three lineages warrant recognition as full species. One lineage, represented by the current subspecies I. $p$. mindorensis, is morphologically distinct, not closely related to the other subspecies of I. philippinus, and separated by a genetic distance of 0.106 from its closest relative, Ixos siquijorensis. A second lineage (I. p. guimarasensis) also is not related to other I. philippinus subspecies. Instead, it is recovered as sister to a clade comprising Ixos rufigularis and Ixos everetti. Two additional subspecies of I. philippinus included in our sampling, I. p. saturatior and I. p. philippinus, were recovered as sister to the clade of I. p. mindorensis and I. siquijorensis. Due to morphological differences (summarized in Fishpool and Tobias, 2005) and deep genetic divergences between these lineages, we recommend that the following taxa be recognized as full species: Ixos mindorensis (Steere, 1890), Ixos guimarasensis (Steere, 1890) and Ixos philippinus (J. R. Forster, 1795), with the last consisting of I. p. saturatior and the nominate form. The subspecies not included in our study, I. p. parkesi, known only from Burias Island, is best retained in I. philippinus until further review. Defining the limits of each of these species is beyond the scope of this study but a natural start to this effort is to use known distribution data of each subspecies (see Kennedy et al., 2000).

We find the generic name Ixos inappropriate for the Philippine radiation of bulbuls in Clade G. The type species I. virescens Temminck, 1825 was not sampled but previous workers (Deignan, 1942; Dickinson and Gregory, 2002) have noted its close 
affinity with I. mclellandii and I. malaccensis. To maintain monophyly of Ixos two options are available: return the species guimarasensis, rufigularis, everetti, mindorensis, siquijorensis and philippinus to the genus Hypsipetes or apply another generic name for this group. We prefer the first option for the sake of taxonomic stability.

Dickinson and Gregory (2002) noted similarities of the species Microscelis amaurotis with other members of the genus Hypsipetes but recommended placing it under its monotypic genus until molecular evidence clarifies its affinity. Our results, as well as that of Moyle and Marks (2006) support placement of the species in the genus Hypsipetes.

Individuals of Alophoixus bres from Palawan and Borneo were recovered as a clade. However, the Palawan form A. b. frater is diverged from Bornean samples by $>0.100$ sequence divergence and, apart from its genetic distinctiveness, is easily distinguished morphologically. Fishpool and Tobias (2005) noted that $A$. b. frater has a slightly greener mantle compared with $A$. $b$. gutturalis. In addition, they differ by the following characters that were based on 21 skin specimens of $A$. b. frater and 3 specimens of $A$. b. gutturalis at the University of Kansas Natural History Museum: belly yellow in $A$. b. frater but pale brown in A. b. gutturalis; undertail coverts yellow in $A$. b. frater but rusty brown in A. b. gutturalis; flanks olive in A. b. frater while light brown in A. b. gutturalis; primaries and retrices dark brown edged olive in $A . b$. 
frater but rusty brown edged rufous in $A$. $b$. gutturalis; throat of $A$. $b$. frater appears darker with more grey at base of throat feathers. Both genetic and morphological data support the recognition of $A$. b. frater (Sharpe, 1877) as a full species.

Considerable genetic divergence exists between named subspecies of other Philippine bulbul species. In Pycnonotus urostictus, pairwise distances greater than 0.040 separate the nominate form, $P$. u. atricaudatus and the group P. u. philippinensis/P. u. basilanicus. As noted above, the Bornean form P. goiavier gourdini is highly divergent (0.071) from the subspecies on Samar P. goiavier samarensis. Each population of Microscelis amaurotis in the Babuyan Islands show differences of 0.014-0.028 between islands, while in contrast, its nominate form on Honshu, Japan shows only $0.015-0.16$ divergence from the subspecies M. a. batanensis in the Batanes Islands. The taxonomic treatment of these named forms requires further study of their morphology, voice and ecology.

\section{B. Biogeography}

The inferred phylogenetic relationships of Philippine bulbuls suggest eight independent colonization events of the Philippine islands - one each by Pycnonotus atriceps, Pycnonotus urostictus, Pycnonotus plumosus cinereifrons, Pycnonotus goiavier, Alophoixus bres frater, Iole palawanensis, Microscelis amaurotis and bulbuls of the genus Ixos. However this is not to say that the Philippine bulbul fauna was assembled only via colonization. We recovered a large clade of bulbuls endemic 
to the Philippines that included a minimum of six species, indicating that substantial in situ speciation also has contributed to contemporary bulbul diversity. The timings of five invasions of the Philippines by bulbuls were evidently very old and may have occurred synchronously as shown by an overlap in the $95 \%$ confidence intervals of ages of nodes that gave rise to Pycnonotus urostictus, P. plumosus, Alophoixus bres, Iole palawanensis and Philippine bulbuls of the genus Ixos (Fig. 3). This overlap is much wider if the node leading to $A$. bres is excluded. This coincidence raises the possibility of a single historical event influencing these splits such as a change in sea levels or a substantial change in climate that severely fragmented habitats.

\section{Patterns of colonization}

Each of the major clades (A, B, and C) include taxa that colonized most of the entire Philippine archipelago (Fig. 3). However, within each of these clades, one lineage colonized either the Palawan region only or the oceanic Philippines region only, but not both. Colonization of each region occurred only once in both Clades A and B, and twice in Clade $\mathrm{C}$. This pattern of invasion suggests that no colonization of the oceanic Philippines by bulbuls took place through Palawan, assuming no extinctions have occurred. This pattern is notable because the Palawan region has for a long time been considered a stepping stone region to the Philippines (Dickerson, 1928; Inger, 1954; Darlington, 1957; Diamond and Gilpin, 1983; Dickinson et al., 1991). In bulbuls, the Palawan region did not serve as an "umbilicus" of Philippine fauna, as Diamond and Gilpin (1983) called it; rather it was a biogeographic cul-de-sac. 


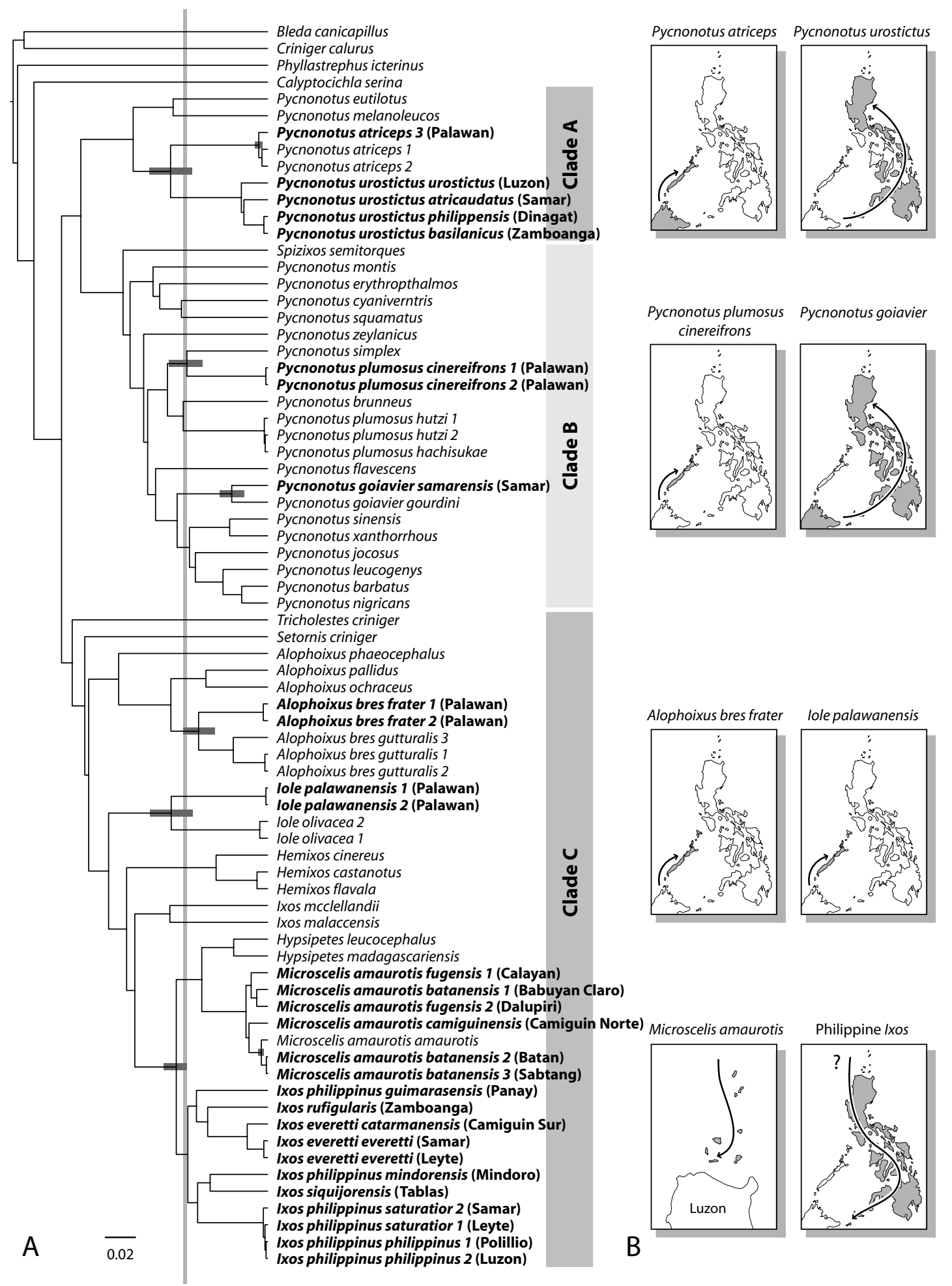

Fig. 3 (A) Ultrametric tree generated from the concatenated dataset. Bars along nodes indicate $95 \%$ C.I. of node heights of genetic splits of Philippine and non-Philippine taxa. Grey vertical bar shows possible coincidence of five splitting events. (B) Maps showing current distribution of taxa and their inferred colonization route. 
Evidence of colonization of the oceanic Philippines from the Sundas through Palawan is lacking in phylogenetic studies of other bird groups that occur across these two regions such as honey-buzzards of the genus Pernis (Gamauf and Haring, 2004), pygmy kingfishers (Moyle et al., 2007) flycatchers of the genus Ficedula (Outlaw and Voelker, 2008), striped babblers of the genus Stachyris (Moyle et al., 2009) and flowerpeckers (Nyári et al., in review). In other vertebrates, Palawan did not act as a gateway to the rest of the Philippines in pit vipers of the genus Trimeresurus (Sanders et al., 2004). Evidence exists for bird taxa reaching only as far as Mindoro through Palawan based on distribution data (e.g. Ceyx erithaca, Spizaetus cirrhatus and Treron curvirostra) and at least one study noted the same colonization pattern in fanged frogs of the genus Rana (Brown and Guttman, 2002). The only evidence from molecular phylogenetic studies we have found for colonization of the Philippine oceanic islands via Palawan is in fruit bats of the genus Cynopterus (Campbell et al., 2004). The role of Palawan as a bridge to the rest of the Philippines appears to have been over-emphasized in previous literature as similarly noted by Jones and Kennedy (2008b).

Colonization of the oceanic islands of the Philippines by bulbuls appears to have followed two routes. The ancestors of two lineages, Pycnonotus urostictus and Pycnonotus goiavier likely invaded from the south through the Sulu archipelago because they are sister to Bornean taxa and are currently present in the Sulus. On the other hand, Microscelis amaurotis likely colonized the Philippines from the north. 
The individual from Japan was embedded inside the Babuyan and Batanes radiation of the species but arrangements in this clade were not well supported. We also lack samples of seven other subspecies found in the rest of its range. The path taken by the ancestor of Philippine bulbuls of the genus Ixos (Clade G) is unclear. Members of its sister Clade F range from East Asia through mainland Asia to Madagascar; no member of this group occurs in the Sundas, suggesting the possibility of a northern invasion route. On the other hand, the southern path through the Sulu archipelago is also possible because the genus sister to Clades F and G, Ixos (Fig.3), includes Bornean residents. Moreover, greater bulbul diversity within Clade $\mathrm{G}$ is present in southern Philippines than its northern half (see below), a pattern that can be expected if the lineage has occupied the south for a longer time. It is unlikely that bulbuls colonized the Philippines from Wallacea, a migration route inferred in other vertebrates (Evans et al., 2003; Esselstyn et al., in review) and hypothesized in other birds (Dickerson, 1928). The only extant bulbuls in the area belong to the genus Thapsinillas and are morphologically similar to Ixos everetti and may be closely related to this taxon (Fishpool and Tobias, 2005). If this is the case, then Thapsinillas may have been an offshoot from the Philippine Ixos radiation. Further work on the phylogenetics and phylogeography of more species occurring throughout the Philippines is required to better understand the importance of each colonization route. 


\section{Diversification of Philippine bulbuls}

The island of Palawan harbors four sympatric bulbul species, each of which is associated with an independent invasion from Borneo. This number comes as no surprise because there is no evidence of in situ diversification on Palawan in birds and very few examples in other vertebrates (e.g., Heaney, 1979). Genetic divergences between Palawan bulbuls and their Bornean sister taxa, with the exception of Pycnonotus atriceps, are deep and thus were likely caused by long periods of isolation. Invasion of Palawan by the ancestors of these highly diverged taxa likely occurred long before the Pleistocene, when land bridges are thought to have appeared between Palawan and Borneo (Heaney, 1986) and served as a passageway for invading fauna. Not only did the origin of the endemic Palawan bulbuls likely predate these land-bridge connections to Borneo, the substantial genetic divergences indicate that the populations did not interbreed during times of overland connection. Even if land connections between Palawan and Borneo were present during the Pleistocene drier grassland habitat may have served as a barrier to interbreeding of these forest species (Bird et al., 2007).

In the oceanic islands of the Philippines the assembly of bulbul fauna took place through a mixture of invasion and in situ diversification. On the islands outside the Mindanao Pleistocene island complex and Cebu, the number of species present is equal to the number of Philippine bulbul clades that reached them. Thus, Luzon harbors three species, Panay, two and small oceanic islands like Tablas, Camiguin 
Sur and the Batanes Islands, one. Upon reaching these northern and western islands, some lineages developed unique forms (e.g. Ixos philippinus mindorensis on Mindoro, Ixos siquijorensis on Tablas) but no further diversification occurred. However, on islands belonging to the Mindanao Pleistocene island complex and on the island of Cebu, the number of species present is greater than the number of bulbul clades that invaded them. The island of Mindanao, for instance, harbors five species of bulbuls whereas only three waves of invasions of the island occurred. Three species on this island, Ixos rufigularis, Ixos everetti, and Ixos philippinus saturatior, belong to the same clade. Higher diversity in the southern Philippines that is not seen in the rest of oceanic Philippines may have resulted because Mindanao had intermittent land connections with the large islands of Leyte, Samar and Bohol (Heaney, 1986; Voris, 2000) and these temporary links may have provided opportunities for vicariant events and back-colonizations between islands. An alternative hypothesis is that these three species arose in allopatry prior to the midMiocene when the Zamboanga peninsula, central Mindanao and eastern Mindanao were distinct islands (Yumul et al., 2008). This explanation is unlikely because it would require several additional long-distance dispersal events and molecular divergences between the taxa do not seem high enough for such an ancient scenario. The island of Cebu, on the other hand, supports two bulbul species belonging to Clade G, the endemic subspecies Ixos siquijorensis monticola and Ixos philippinus saturatior. We lack samples from Cebu so the mode of assembly of bulbuls on the island is uncertain. If $I$. s. monticola is more closely related to other forms of the $I$. 
siquijorensis than it is to I. p. saturatior as suggested by current taxonomy then Cebu was likely the subject of two waves of immigration from neighboring islands.

Within the oceanic islands of the Philippines diversification patterns do not follow boundaries of late Pleistocene islands. We lack extensive sampling from different islands in each island group but some results are clear from the data. For instance, Luzon and Mindanao bulbuls are indistinct in Ixos philippinus; whereas in Pycnonotus urostictus, Samar and Mindanao birds are as distinct as Samar and Luzon individuals. Diversification patterns not congruent with late Pleistocene island configurations have also been observed in other studies of birds (e.g., Jones and Kennedy, 2008a, 2008b) and exceptions noted in other vertebrates (Esselstyn, et al., in review).

This study proposes to increase the number of bulbul species endemic to the Philippines from six to ten. The subspecies Ixos siquijorensis cinereiceps from Tablas Island will likely be split from the nominate form on Siquijor Island because considerable vocal and plumage differences have been noted (Allen, 2006). This result underscores how Philippine bird diversity is currently underestimated (see Peterson, 2006). Further molecular systematic studies on other bird families and with greater island sampling are recommended to better understand the history of avian diversification in this archipelago. 


\section{ACKNOWLEDGEMENTS}

We are grateful to J. Reynon, N. Puna, J. Fernandez and R. Fernandez for assistance

in the field, H. Shult for assistance in laboratory work, and J. Oaks for assistance with using BEAST. We thank D. Willard and J. Bates (FMNH), R. Brumfield (LSUMNS) and the Sabah Parks museum for specimen loans. J. Esselstyn and A. T. Peterson provided useful comments on the first draft of the manuscript. We thank the Department of Environment and Natural Resources and the Protected Areas and Wildlife Bureau for facilitating research and export permits. This study was conducted with financial support from the National Science Foundation (DEB 0743576 and DEB 0743491 to R. G. M.). 


\section{REFERENCES}

Allen, D., 2006. New records and other observations of birds on the island of Tablas, Romblon province, Philippines. Forktail 22, 77-84.

Bird, M.I., Boobyer, E.M., Bryant, C., Lewis, H.A., Paz, V., Stephens, W. E., 2007. A long record of environmental change from bat guano deposits in Makangit Cave, Palawan, Philippines. Earth Envi. Sci. Trans. R. Soc. Edinburgh 98, 59-69.

Buckley, T.R., Cunningham, C.W., 2002. The effects of nucleotide substitution model assumptions on estimates of nonparametric bootstrap support. Mol. Biol. Evol. $19,394-405$.

Bures, S., Nadvornik, P., Saetre, G.-P., 2002. Hybridization and apparent hybridization between meadow pipit (Anthus pratensis) and water pipit ( $A$. spinoletta). Hereditas 136, 254-256.

Campbell, P., Schneider, C.J., Adnan, A. M., Zubaid, A., Kunz, T.H., 2004. Phylogeny and phylogeography of Old World fruit bats in the Cynopterus brachyotis complex. Mol. Phylogenet. Evol. 33, 764-781. 
Chesser, R.T., 1999. Molecular systematics of the rhinocryptid genus Pteroptochos. Condor 101, 439-446.

Deignan, H.G., 1942. Nomenclature of certain Pycnonotidae. Auk 59, 313-315.

Dickerson, R.E., 1928. Distribution of Life in the Philippines. Bureau of Science, Manila.

Dickinson, E.C., (ed.) 2003. The Howard and Moore complete checklist of the birds of the world, $3^{\text {rd }}$ edn. Princeton University Press, Princeton, New Jersey.

Dickinson, E.C., Gregory, S.M.S., 2002. Systematic notes on Asian birds. 24. On the priority of the name Hypsipetes Vigors, 1831, and the division of the broad genus of that name. Zool. Verh. Leiden 340, 75-91.

Dickinson, E.C., Kennedy, R.S., Parkes, K.C., 1991. The birds of the Philippines: an annotated check-list. British Ornithologists' Union. Tring, U. K.

Drovetski, S.V., Zink, R.M., Rohwer S., Fadeev I.V., Nesterov E.V., Karagodin I., Koblik E.A., Red'kin Y.A., 2004. Complex biogeographic history of a Holarctic passerine. Proc. R. Soc. Lond. B. 21, 545-551. 
Drummond A.J., Rambaut A., 2007. BEAST: Bayesian evolutionary analysis by sampling trees. BMC Evol. Biol. 7, 214.

Drummond A. J., Ho S.Y.W., Phillips M.J., Rambaut, A., 2006. PLoS Biol. 4, e88.

Esselstyn, J.A., Timm, R.M., Brown, R.M. (In review) Do geological or climatic processes drive speciation in dynamic archipelagos? The evolution of shrew diversity on SE Asian islands. Evolution.

Evans, B.J., Brown, R.M., McGuire, J.A., Supriatna, J., Andayani, N., Diesmos, A., Iskandar, D., Melnick, D.J., Cannatella, D.C., 2003. Phylogenetics of fanged frogs: testing biogeographical hypotheses at the interface of the Asian and Australian faunal zones. Syst. Biol. 52, 794-819.

Filardi, C.E., Moyle, R.G., 2005. Single origin of a pan-Pacific bird group and upstream colonization of Australasia. Nature 438, 216-219.

Fishpool, L.D.C., Tobias, J.A., 2005. Family Pycnonotidae (Bulbuls). In: del Hoyo, J., Elliott, A., Christie, D.A. (Eds.), Handbook of the Birds of the World, Vol. 10 Cuckoo-shrikes to Thrushes. Lynx Edicions, Barcelona, pp. 124-251. 
Gamauf, A., Haring, E., 2004. Molecular phylogeny and biogeography of Honeybuzzards (genera Pernis and Henicopernis). J. Zool. Syst. Evol. Res. 42, 145-153.

Goldman, N., Anderson, J.P., Rodrigo, A.G., 2000. Likelihood based tests of topologies in phylogenetics. Syst. Biol. 49, 652-670.

Hall, R., 2002. Cenozoic geological and plate tectonic evolution of SE Asia and the SW Pacific: computer-based reconstructions, model and animations. J. Asian Earth Sci. 20, 353-431.

Hasegawa, M.Y., Kishino, H., Yano, T., 1985. Dating of the human-ape splitting by a molecular clock of mitochondrial DNA. J. Mol. Evol. 21, 160-174.

Hackett, S.J., 1996. Molecular phylogenetics and biogeography of tanagers in the genus Ramphocelus (Aves). Mol. Phylogenet. Evol. 5, 368-382.

Heaney, L.R., 1979. A new species of tree squirrel (Sundasciurus) from Palawan Island, Philippines (Mammalia: Sciuridae). Proc. Biol. Soc. Wash. 92, 280-286.

Heaney, L.R., 1986. Biogeography of mammals in SE Asia: estimates of rates of colonization, extinction and speciation. Biol. J. Linn. Soc. 28, 127-165. 
Huelsenbeck, J.P., Ronquist, F., 2001. MRBAYES: Bayesian inference of phylogeny. Bioinformatics 17, 754-755.

Jansa, S.A., Barker, F.K., Heaney, L.R., 2006. The pattern and timing of diversification of Philippine endemic rodents: evidence from mitochondrial and nuclear gene sequences. Syst. Biol. 55, 73-88.

Johansson, U., Fjeldså, J., Lokugallapati, L.G.S. \& Bowie, R.C.K., 2007. A nuclear DNA phylogeny and proposed taxonomic revision of African greenbuls (Aves, Passeriformes, Pycnonotidae). Zool. Scripta 36, 417-427.

Jones, A.W., Kennedy, R.S., 2008a. Plumage convergence and evolutionary history of the Island Thrush in the Philippines. Condor 110, 35-44.

Jones, A.W., Kennedy, R.S., 2008b. Evolution in a tropical archipelago: comparative phylogeography of Philippine fauna and flora reveals complex patterns of colonization and diversification. Biol. J. Linn. Soc. 95, 620-639.

Kennedy, R.S., Gonzales, P.C., Dickinson, E.C., Miranda, H.C., Fisher, T.H., 2000. A guide to the birds of the Philippines. Oxford University Press, Oxford. 
Moyle, R.G., Marks, B.D., 2006. Phylogenetic relationships of the bulbuls (Aves:

Pycnonotidae) based on mitochondrial and nuclear DNA sequence data. Mol.

Phylogenet. Evol. 40, 687-695.

Moyle, R.G., Schilthuizen, M., Rahman, M.A., Sheldon, F.H., 2005. Molecular

phylogenetic analysis of the white-crowned forktail Enicurus leschenaulti in Borneo.

J. Avian Biol. 36, 96-101.

Moyle, R.G., Fuchs, J., Pasquet, E., Marks, B.D., 2007. Feeding behavior, toe count, and the phylogenetic relationships among alcedinine kingfishers (Alcedininae). J. Avian Biol. 38, 317-326.

Moyle, R.G., Filardi, C.E., Smith, C.E., Diamond, J., 2009. Explosive Pleistocene diversification and hemispheric expansion of a "great speciator." Proc. Nat. Acad. Sci. U.S.A. 106, 1863-1868.

Nyári, Á.S., Peterson, A.T., Rice, N.H., Moyle, R.G., In review. Phylogenetic relationships of flowerpeckers (Aves: Dicaeidae): novel insights into the evolution of a tropical passerine clade. Mol. Phylogenet. Evol.

Nylander, J.A.A., 2004. MrModeltest, a program to evaluate the fit of several models of evolution to a given data and unrooted tree (version 2.2). Program distributed by 
the author. Evolutionary Biology Centre, Uppsala University, Sweden. Available at http://www.abc.se/ nylander/.

Ong, P.S., Afuang, L.E., Rosell-Ambal, R.G. (Eds.) 2002. Philippine Biodiversity Conservation Priorities: A Second Iteration of the National Biodiversity Strategy and Action Plan. Department of Environment and Natural Resources-Protected Areas and Wildlife Bureau, Conservation International Philippines, Biodiversity Conservation Program-University of the Philippines Center for Integrative and Development Studies, and Foundation for the Philippine Environment, Quezon City, Philippines.

Outlaw, D.C., Voelker, G., 2008. Pliocene climatic change in insular Southeast Asia as an engine of diversification in Ficedula flycatchers. J. Biogeogr. 35, 739-752.

Peterson, A.T., 2006. Taxonomy is important in conservation: a preliminary reassessment of Philippine species-level bird taxonomy. Bird Conserv. Intl. 16, 155173.

Prychitko, T.M., Moore W.S., 1997 The utility of DNA sequences of an intron from the $\beta$-fibrinogen gene in phylogenetic analysis of woodpeckers (Aves: Picidae). Mol. Phylogenet. Evol. 8, 193-204. 
Rand, A.L., Deignan, H.G., 1960. Family Pycnonotidae. In: Mayr E., Greenway Jr., J. (Eds.) Check-list of Birds of the World. IX. Cambridge, MA, pp. 221-300.

Ronquist, F., Huelsenbeck, J.P., 2003. MRBAYES 3: Bayesian phylogenetic inference under mixed models. Bioinformatics 19, 1572-1574.

Sanders, K., Malhotra, A., Thorpe, R., 2004. Ecological diversification in a group of Indomalayan pitvipers (Trimeresurus): convergence in taxonomically important traits has implications for species identification. J. Evol. Biol. 17, 721-731.

Sheldon, F.H., Whittingham, L.A., Moyle, R.G., Slikas, B. \& Winkler, D.W., 2005. Phylogeny of swallows (Aves: Hirundinidae) estimated from nuclear and mitochondrial DNA sequences. Mol. Phylogenet. Evol. 35, 254-270.

Sheldon, F.H., Lohman, D.J., Lim, H.C., Zou, F., Goodman, S.M., Prawiradilaga, D.M., Winker, K., Braile, T.M., Moyle, R.G. (In press) Phylogeography of the magpie-robin species complex (Aves: Turdidae: Copsychus) reveals a Philippine species, and interesting isolating barrier, and unusual dispersal patterns in the Indian Ocean and Southeast Asia. J. Biogeogr.

Swofford, D.L., 2002. PAUP*: Phylogenetic Analysis Using Parsimony (*and other methods). Sinauer Associates, Sunderland, MA. 
Voris, H.K., 2000. Maps of Pleistocene sea levels in Southeast Asia: shorelines, river systems and time durations. J. Biogeogr. 27, 1153-1167.

Yumul, G.P. Jr., Dimalanta, C.B., Maglambayan, V.B., Marquez, E. J., 2008.

Tectonic setting of a composite terrane: A review of the Philippine island

arc system. Geosci. J. 12, 7-17.

Zwickl, D., 2008. GARLI, a program that performs phylogenetic searches on aligned sequence datasets using the maximum-likelihood criterion (version 0.96). Available at http://garli.nescent.org/ (last accessed 12 December 2008). 